Chapter 1

\title{
Environmental Changes and the Geographic Spreading of American Cutaneous Leishmaniasis in Brazil
}

\author{
Elizabeth F. Rangel, Simone M. da Costa and \\ Bruno M. Carvalho \\ Additional information is available at the end of the chapter \\ http://dx.doi.org/10.5772/57207
}

\section{Introduction}

Global human population is facing the impacts of centuries of constant changes in natural environments. Impacts in the dynamics of infectious diseases are not only expected, but can already be noticed. Vector-borne diseases are particularly susceptible to environmental changes, since their occurrence depends on the ecological balance between different species in complex transmission cycles [1-3]. Leishmaniases are among the vector-borne diseases most affected by this ecological chaos driven by human actions [4], and one of the expected impacts is the expansion of its geographical distribution [5-7].

Leishmaniases are among the world's six most neglected diseases, affecting indistinctively men, women and children. Usually they occur among the poorest of the poor, mainly in developing countries, contributing to establishment and maintenance of social inequities [7]. They can be divided in two main clinical forms: visceral leishmaniasis (VL) and cutaneous leishmaniasis (CL). Despite this simple classification, a wide clinical spectrum is observed, mostly because of the high diversity of parasites (Trypanosomatidae of Leishmania genus), vectors (Phlebotominae sand flies) and reservoir hosts (mammals of several orders) involved in its transmission cycles [7,8].

The geographical distribution of leishmaniases includes 98 countries in American, European, Asiatic, African and Australian continents. The World Health Organization estimates the yearly occurrence of about 200,000 to 400,000 VL human cases and 700,000 to 1.2 million CL human cases. More than $90 \%$ of global VL cases are recorded in six countries: India, Bangladesh, Sudan, South Sudan, Ethiopia and Brazil. Cutaneous leishmaniasis is more widely distributed, with about one-third of cases occurring in tropical regions of the Americas, the 
Mediterranean basin, western and central Asia. In the American continent, Brazil is the country with the highest estimated incidences of both visceral and cutaneous leishmaniases [9].

The distribution of leishmaniases in the world can be partially explained by its widely distributed vectors. The sand flies are small insects (adults of about 3-5 mm) from order Diptera, family Psychodidae, subfamily Phlebotominae. Although occurring mainly in the tropical, hottest areas of the world (Latin America, South Europe, Africa, South Asia and Australia), their distribution stretches north and south to latitudes of over $40^{\circ}$, such as in Germany [10] and Argentinean Patagonia [11]. Sand flies have primarily crepuscular and nocturnal habits, but adults were captured during the day in dense forests [12], caves [13] and dark, humid animal shelters [14]. Only females are haematophagous and thus are related with Leishmania transmission. Their broad feeding habits contribute to the transmission of pathogens between hosts in sylvatic and peridomestic areas [15, 16]. Of approximately 900 described sand fly species, no more than 70 have been implicated in leishmaniases transmission [17]. All New World vector species belong to Lutzomyia genus, while the Old World vectors are grouped in Phlebotomus genus [15, 18].

In Brazil, the concept of leishmaniases as a sylvatic zoonosis is restricted to the Amazon Forest, Atlantic Forest fragments and parts of Cerrado. A new transmission profile has emerged, driven mostly by human-made environmental changes. In past decades, human migration of different origins and purposes resulted in major deforestation and unplanned settlements. These changes favor the dispersion of sylvatic animals (some Leishmania reservoir hosts) and sand flies (especially those species with eclectic feeding habits) to peridomestic areas, where new transmission cycles may establish close to human dwellings [19-21].

This new transmission profile is especially evident for American Cutaneous Leishmaniasis (ACL), which is caused by a variety of Leishmania parasites. Although some clinical manifestations are more frequently associated with a particular Leishmania species or subgenus (Viannia or Leishmania), none is unique to a species. In addition, a substantial but variable proportion of infections are asymptomatic. Human cases have been occurring with different clinical forms, including localized, disseminated, diffuse and atypical cutaneous and mucosal lesions. Different species of sand flies and reservoirs interact in complex transmission cycles, with particular ecoepidemiological features on each disease focus [22, 23].

According to Brazilian Ministry of Health [23], ACL can be categorized in three epidemiological patterns:

1. Sylvatic: In this case, transmission occurs in primary vegetation areas, where the disease is characterized as a strictly sylvatic zoonosis. Humans get infected occasionally when entering these areas, where the enzootic cycle is maintained;

2. Sylvatic/occupational and impacted areas: This pattern is associated with exploitation of natural environments and deforestation, originated mostly from constructions of roads, hydroelectric power plants, human settlements, wood extraction, agricultural activities, military training and ecotourism. In this case, humans are more intensively exposed to vector contact; 
3. Rural/periurban (colonization areas): ACL occurrence is related to human migration, occupation of slopes and aggregation in periurban areas associated with secondary and residual vegetation. Synanthropic and domestic animals such as dogs, horses and rodents are suggested reservoir hosts.

Brazil is currently facing an increasing geographical expansion of ACL, with a shift from the classical predominant epidemiological pattern 1 to frequent observations of pattern 2. All of its states have records of the disease, with a growing number of municipalities affected each year (Figure 1).
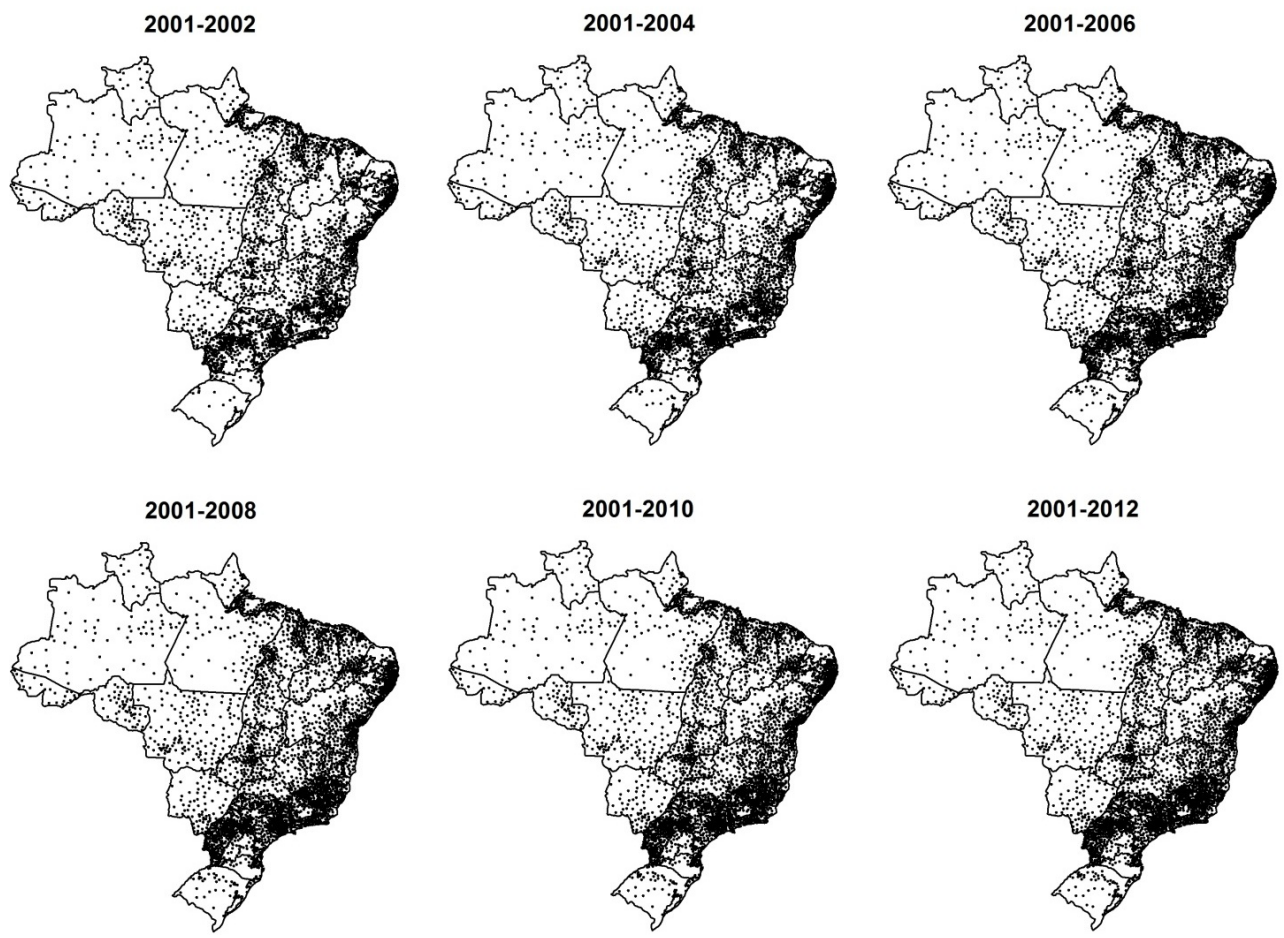

Figure 1. Brazilian municipalities with records of American Cutaneous Leishmaniasis, 2001 to 2012. Each point on the map represents one municipality with $\mathrm{ACL}$ human case records

This expansion can probably be explained by the growing environmental changes, which in turn affect vector behavior. Some ACL vector species have been showing evidences of adaptation to man-modified environments, establishing in peridomestic areas, even in outskirts of large cities [22,23]. In this case, two sand fly species are particularly good examples, in different ecoepidemiological situations: Lutzomyia (Nyssomyia) whitmani and Lutzomyia (Nyssomyia) flaviscutellata. On the following sections the geographical distribution in Brazil and relation with ACL transmission of these species are presented. 


\section{Lutzomyia (Nyssomyia) whitmani (Antunes \& Coutinho 1939)}

Lutzomyia (N.) whitmani was described by Antunes \& Coutinho in 1939 [24] as Flebotomus whitmani in honor of Dr. Whitman, from Rockefeller Foundation, an institute that collaborated with the Brazilian government at the time in the Yellow Fever Service. The new species was described based on male and female specimens captured in Ilhéus municipality, Bahia state. This species can be observed in all five regions of Brazil and, in the American continent it is also present in Argentina, French Guiana, Paraguay and Peru [7, 18].

The role of L. (N.) whitmani as ACL vector is evident throughout the Brazilian territory. The first observation of its importance in ACL transmission cycle was made in São Paulo state, where females were caught naturally infected by flagellates, possibly Leishmania [25]. In the same state, the biology of some sand fly species was studied, and L. (N.) whitmani was frequently found in deforested areas [26]. According to Pessoa \& Coutinho [25], this species is considered highly anthropophilic, constantly invading houses for biting humans.

Between decades of 1930 and 1940, during the human colonization of South and Southeast Brazilian regions, ACL transmission was related with L. (N.) whitmani, with its occurrence mainly in sylvatic areas [27]. At this time, this sand fly species used to inhabit mainly forests. Man and domestic animals were bitten when they entered these areas or when houses were built near or inside forests [26]. Other studies on the ecology of $L$. (N.) whitmani showed aspects of its natural breeding places, monthly variation, high density and adaptation to domestic areas [28].

In Brazil, L. (N.) whitmani was already detected in 634 of its 5566 municipalities, occurring in all 27 federative units (Figure 2). The states with the higher spatial aggregation of municipalities with the vector occurrence are Pernambuco, Minas Gerais, São Paulo and Paraná, which are also areas of high concentration of ACL human cases [29] (see Figure 1).

Lutzomya (N.) whitmani is widely distributed across Brazilian biomes. Its presence was recorded in Amazon, Cerrado, Caatinga, Atlantic Forest and Pantanal (Figure 3), occurring mainly in Cerrado and Atlantic Forest [30]. When observing its occurrence in different Brazilian vegetation types, the vector occurs in municipalities with predominance of dense ombrophilous forest, deciduous ombrophilous forest, semideciduous ombrophilous forest, savannah and steppe (Figure 4). The species was not observed in municipalities predominantly covered by marshes and sandbanks [29].

In São Paulo state, L. (N.) intermedia and L. (N.) whitmani were the predominant species during deforestation of primary forests [28]. However, as deforestation continued to expand, L. (N.) whitmani showed lower abundances, suggesting that this species would be more dependent of primary forest than L. (N.) intermedia. On the other hand, L. (N.) whitmani was found frequently inside houses built near the forest. In Southeast Region, this species can be found during all months of the year [22, 26]. In São Roque municipality, São Paulo state, L. (N.) whitmani was the predominant sand fly species among Leishmania (V.) braziliensis transmission areas [31], showing higher abundances in the hotter months of the year [32]. 


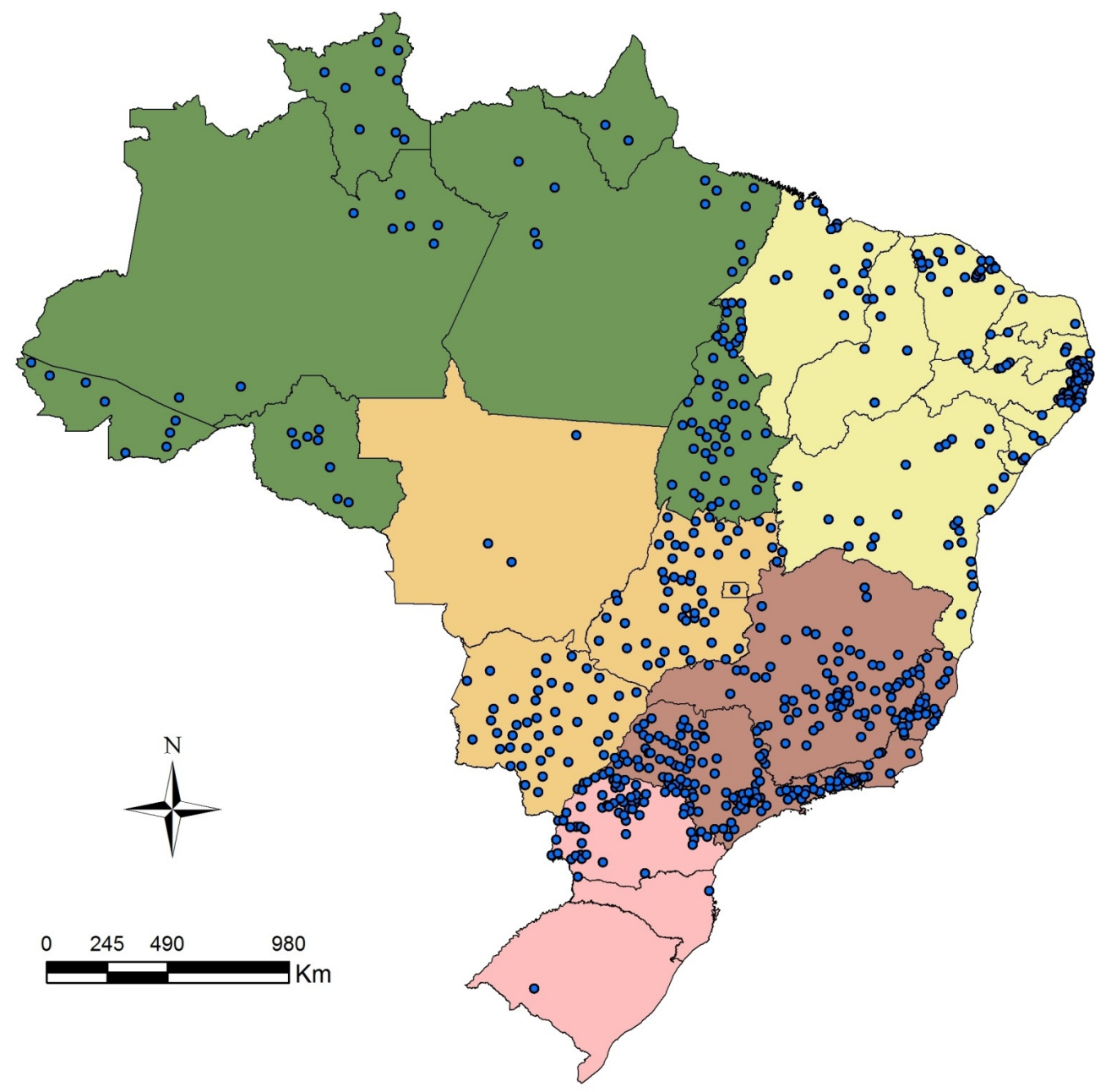

Legend

Brazilian Regions Municipalities with ACL Vectors

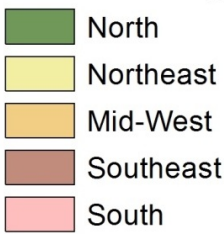

- Lutzomyia (N.) whitmani

Figure 2. Brazilian municipalities with Lutzomyia (Nyssomyia) whitmani occurrence 


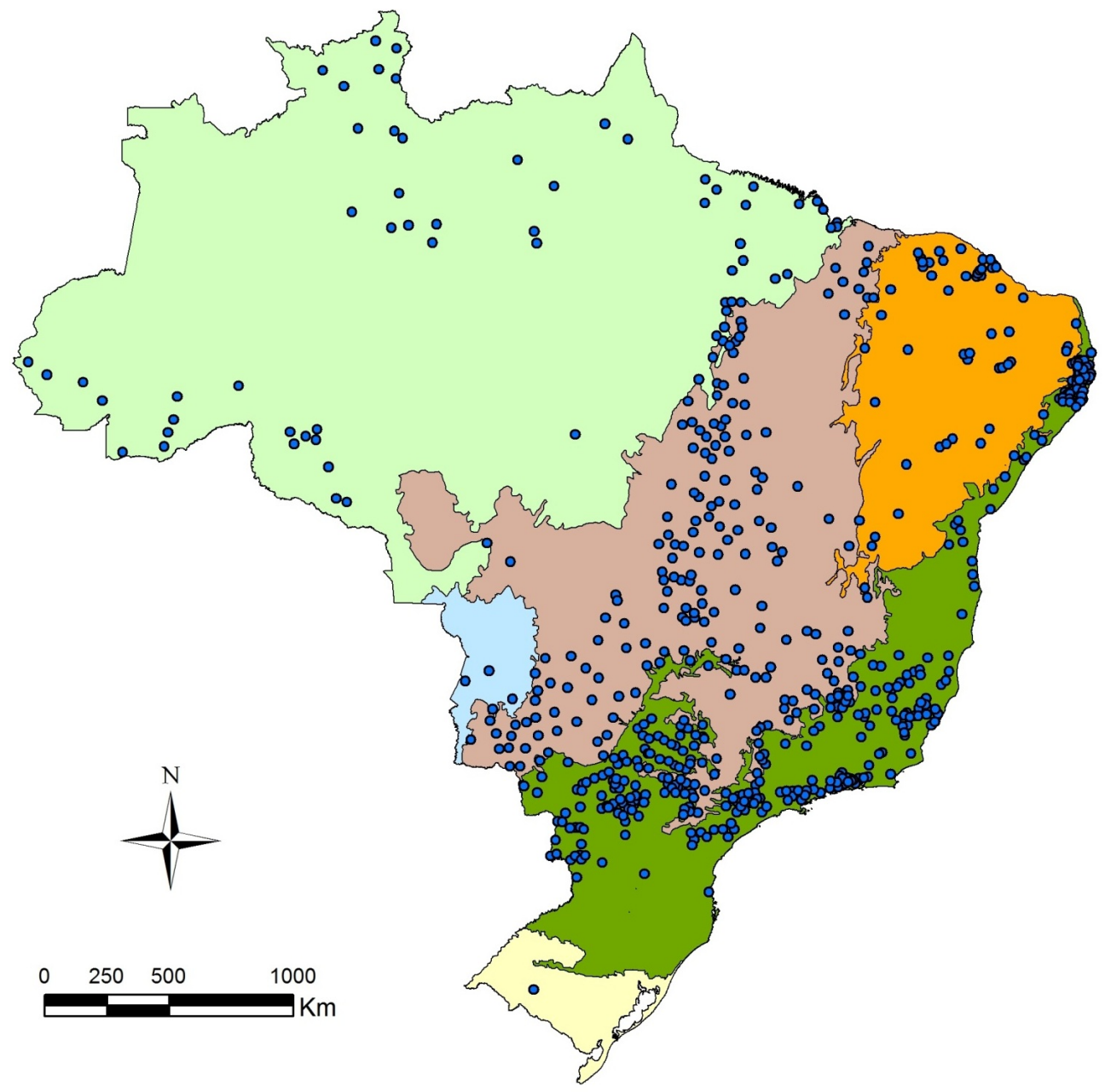

\section{Legend}

Biomes

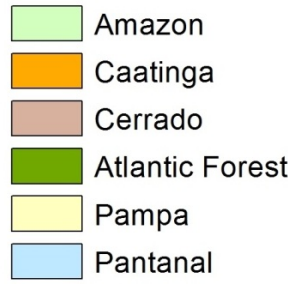

\section{Municipalities with ACL Vectors}

- Lutzomyia (N.) whitmani

Figure 3. Brazilian municipalities with Lutzomyia (Nyssomyia) whitmani occurrence and biomes 


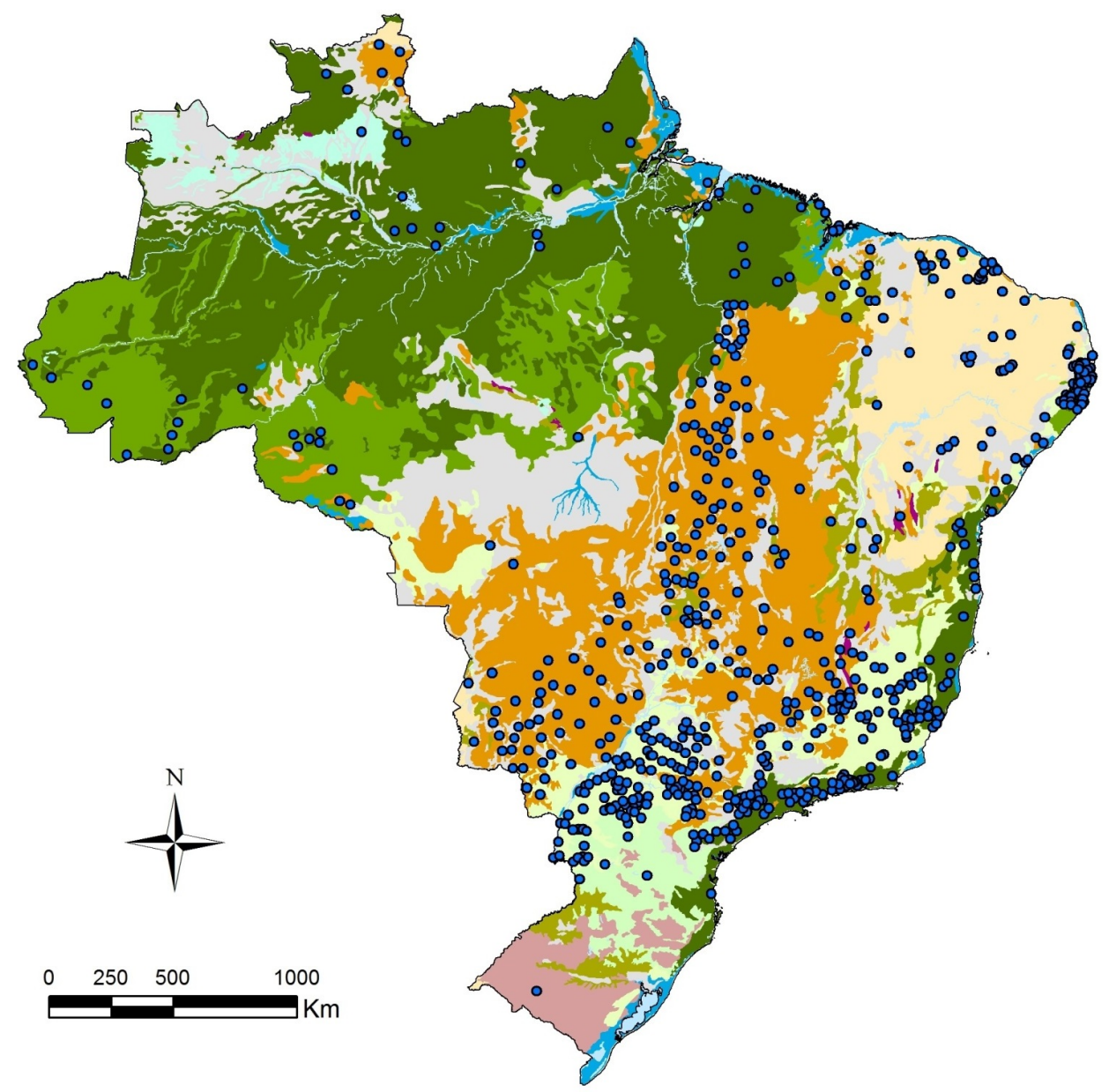

\section{Legend}

\section{Municipalities with ACL Vectors}

- Lutzomyia (N.) whitmani

\section{Vegetation Type}

\begin{tabular}{|l|l|}
\hline Dense Ombrophilous Forest & Savannah \\
\hline Open Ombrophilous Forest & Savannah/Steppe \\
\hline Mixed Ombrophilous Forest & Steppe \\
\hline Semideciduous Ombrophilous Forest & Pioneer Vegetation Areas \\
\hline Deciduous Ombrophilous Forest & Ecological Tension Areas \\
\hline Campinarana & Water \\
\hline
\end{tabular}

Figure 4. Brazilian municipalities with Lutzomyia (Nyssomyia) whitmani occurrence and vegetation types 
This species was also observed in Atlantic Forest protected areas and inside houses near the forest in Rio de Janeiro state [33]. In the same state, studies performed in rural areas of ACL transmission showed the co-occurrence of $L$. (N.) intermedia and L. (N.) whitmani biting humans. In peridomestic areas, $L$. (N). intermedia was predominant, while $L$. (N.) whitmani was more frequent in the nearest forest. With this spatial separation, the authors suggested that both species would be sharing Leishmania $(V$.) braziliensis transmission on the same focus, throughout the year. Lutzomyia (N.) whitmani was captured during all year, but was more frequent in months with lower temperatures [34].

Also in Southeast region, besides São Paulo and Rio de Janeiro states, L. (N.) whitmani was associated with Leishmania (Viannia) braziliensis transmission in Caratinga (Minas Gerais state) and in a mountainous region of Afonso Cláudio (Espírito Santo state) [35, 36].

In South Brazil, L. (N.) whitmani is probably associated to ACL transmission in Paraná state. Studies performed in the north of this state detected it as predominant sand fly species and naturally infected by Leishmania (V.) braziliensis parasites [37].

Leishmania (V.) braziliensis in Northeast region is also probably transmitted by L. (N.) whitmani. In Bahia and Ceará states this vector shows similar habits to the Southeast region populations: high anthropophily and presence in domestic areas [38-40]. In Ceará state, L. (N.) whitmani was found naturally infected by Leishmania of Viannia subgenus [41]. Afterwards, new infections were detected and the parasite characterization confirmed to be Leishmania (V.) braziliensis [42]. Other evidences of this vector's role in ACL transmission in the region were its high abundance and anthropophily [40, 42].

In Bahia state, L. (N.) whitmani was found naturally infected by Leishmania (V.) braziliensis in Três Braços [43]. This finding, associated with the high frequency of this sand fly in peridomestic and domestic areas allowed the hypothesis of occurrence of a domestic transmission cycle in this area [44]. In Ilhéus municipality, L. (N.) whitmani was suggested as ACL vector, considering its almost absolute predominance over other sand fly species (99.7\%), its high anthropophily and its occurrence on every sand fly capture point, most of them coincident with areas of ACL human cases [40].

In the Mid-West Region, in Corguinho municipality (Mato Grosso do Sul state), Leishmania (V.) braziliensis was isolated from every tested ACL patient by monoclonal antibodies. Lutzomyia (N.) whitmani was suggested as vector because it was observed in high abundances and anthropophilic [45]. Furthermore, its predominance over other sand flies was observed in eight of ten ecotopes studied in the locality. Lutzomyia (N.) whitmani was present both in ground level and in the forest canopy, suggesting its eclectic feeding habits on mammals and birds. Although in this locality the species is not very common in peridomestic areas, its high abundance and anthropophily are strong evidences of its role in ACL transmission [46].

The behavior of L. (N.) whitmani in North region seems to be different from other regions. In these areas, the species was considered mainly sylvatic, being captured on tree trunks and canopies, besides showing low attractiveness for humans [47]. Afterwards, novel studies confirmed such observations and suggested that, if the species were to be anthropophilic, it would be only in some situations [48, 49]. In 1989, in Pará state, a parasite was isolated from 
L. (N.) whitmani, and after its characterization as Leishmania (V.) shawi, the sand fly species was suggested as its vector [50].

\section{Lutzomyia (Nyssomyia) flaviscutellata (Mangabeira 1942)}

Lutzomyia (N.) flaviscutellata was described by Mangabeira [51] as Flebotomus flaviscutellatus, based on two male specimens captured in Belém (Pará state). Later, Sherlock \& Carneiro [52] described a female collected in Salvador (Bahia state), although its identification has been questioned by several authors [18, 27, 53]. At the same time, the species Phlebotomus apicalis was described by Floch \& Abonnenc [54] in French Guiana. Three years later, after a review of the specimens, P. apicalis was considered synonym of L. (N.) flaviscutellata [55].

In the following years, descriptions of L. (N.) olmeca [56], L. (N.) olmeca bicolor [53] and L. (N.) olmeca nociva [57], all of them morphologically similar to L. (N.) flaviscutellata, led some authors to consider these four species as the "L. flaviscutellata complex" [58]. However, they are all currently considered valid species, with more recent taxonomic reviews supporting their status $[18,59]$.

Lutzomyia (N.) flaviscutellata is currently widely distributed across Latin America, occurring in Bolivia, Brazil, Colombia, Ecuador, French Guiana, Peru, Suriname, Trinidad and Venezuela $[7,18]$.

This sand fly species is associated with Leishmania (Leishmania) amazonensis transmission in Brazil. This parasite, when infecting humans, can cause localized cutaneous lesions and eventually develop a more severe clinical form, diffuse cutaneous leishmaniasis (DCL). This clinical form is rare, with chronic development, where the immunodepressed patient shows frequent relapses and insufficient responses to available therapies [60].

The first observation of this sand fly's role in ACL transmission cycle was from a study in the Utinga forest, an Amazon area in Belém municipality (Pará state) [61]. In this area, wild rodents of Proechimys and Oryzomys genus were captured with cutaneous lesions on tails and feet, from where Leishmania parasites were isolated. These rodents were then used as baits and $98 \%$ of captured sand flies were L. (N.) flaviscutellata. Captured sand flies were dissected and flagellates were isolated from eight females.

Studies of the feeding habits of $L$. (N.) flaviscutellata showed higher preference for small sylvatic rodents (Proechimys sp., Oryzomys sp.), agoutis (Dasyprocta sp.) and porcupines (Coendou sp.), having the species also fed on opossums (Philander sp.), monkeys (Saimiri sp.) and chickens (Gallus gallus). Few females fed on humans, so the authors considered the species as having low anthropophily [62]. This preference for biting small rodents indicates that captures of this species tend to be more efficient when using animal baited traps, such as the Disney trap [63].

Despite its strong zoophilic habits and low anthropophily, Lutzomyia (N.) flaviscutellata has recently been captured in peridomestic areas, suggesting its dispersion to human dwellings [64-67]. This hypothesis is plausible, since the species also occurs in secondary forests in the 
Amazon. In a study performed in the late 1980s in Pará state, L. (N.) flaviscutellata was the predominant sand fly species in an area where the primary forest was replaced with exotic trees (Pinus and Gmelina), with occasional captures in peridomestic areas of houses near the forest [68]. In a review of the Amazonian ACL transmission cycles, L. (N.) flaviscutellata was considered one of the few vector species that could adapt to deforestation and become peridomestic [69].

In Brazil, L. (N.) flaviscutellata was detected in 131 municipalities, mostly in North and MidWest regions, with occurrences also in Southwest and Northeast regions (Figure 5).

Lutzomya (N.) flaviscutellata is considered mainly an Amazonian species, although it can also be found in Cerrado and some few occurrences were recorded in Atlantic Forest, Caatinga and Pantanal (Figure 6).

In the Amazon, L. (N.) flaviscutellata is more commonly found in seasonally flooded areas of "igapó forests", when compared with non-flooded areas of "terra-firme forests" [70]. Its vertical distribution was also studied in the Amazon. The species has a very low flight, with 26 times more specimens captured 0.2 meters above ground than at 1.2 meters. This observation reinforces its association with small rodents and the fact that human cutaneous lesions caused by Leishmania (L.) amazonensis are mainly located in the lowest parts of the body [71].

The species was also captured in peridomestic areas of Manaus (Amazonas state) [72], Ilha de Marajó (Pará state) [73] and Santarém (Pará state) [74]. Other examples of surveyed Amazon forest areas of the North region with records of $L$. (N.) flaviscutellata include the states: Acre [75, 76], Amazonas [13, 76-79], Amapá [80], Pará [61, 62, 68, 70, 81], Rondônia [82, 83] and Roraima $[84,85]$.

Also in the North region, Tocantins state has most of its area covered by Cerrado. It was in this biome that $L$. (N.) flaviscutellata was captured during a four-year sand fly fauna monitoring in the ACL endemic areas of Porto Nacional and Guaraí municipalities. This vector species was found in peridomestic captures in rural settlements and periurban areas [66, 67] and was suggested as Leishmania (L.) amazonensis vector in Porto Nacional [66]. In municipalities of the south of the same state, L. (N.) flaviscutellata was captured near houses in areas directly and indirectly impacted by a hydroelectric power plant construction in Tocantins River [86].

In Bela Vista municipality (Mato Grosso do Sul State, Mid-West region), an ACL outbreak associated with Leishmania (L.) amazonensis in a military training unit led to a sand fly fauna monitoring during years 2004 to 2006. Using light traps, few specimens of L. (N.) flaviscutellata were caught [87]. When a modified Disney trap baited with hamsters (Mesocricetus auratus) was used, L. (N.) flaviscutellata was the species with the highest female abundance [88]. Despite its capture with these methodologies, some females were also captured in white and black Shannon traps [89], suggesting that the species can also feed on humans, and therefore be a possible Leishmania (L.) amazonensis vector in this locality [87].

The sand fly fauna of an ecotourism area in Bonito (Mato Grosso do Sul state) was studied. In Cerrado areas, $L$. (N.) flaviscutellata was caught with light traps mainly inside the forest, but it was also found in yards and kennels of houses [64]. 


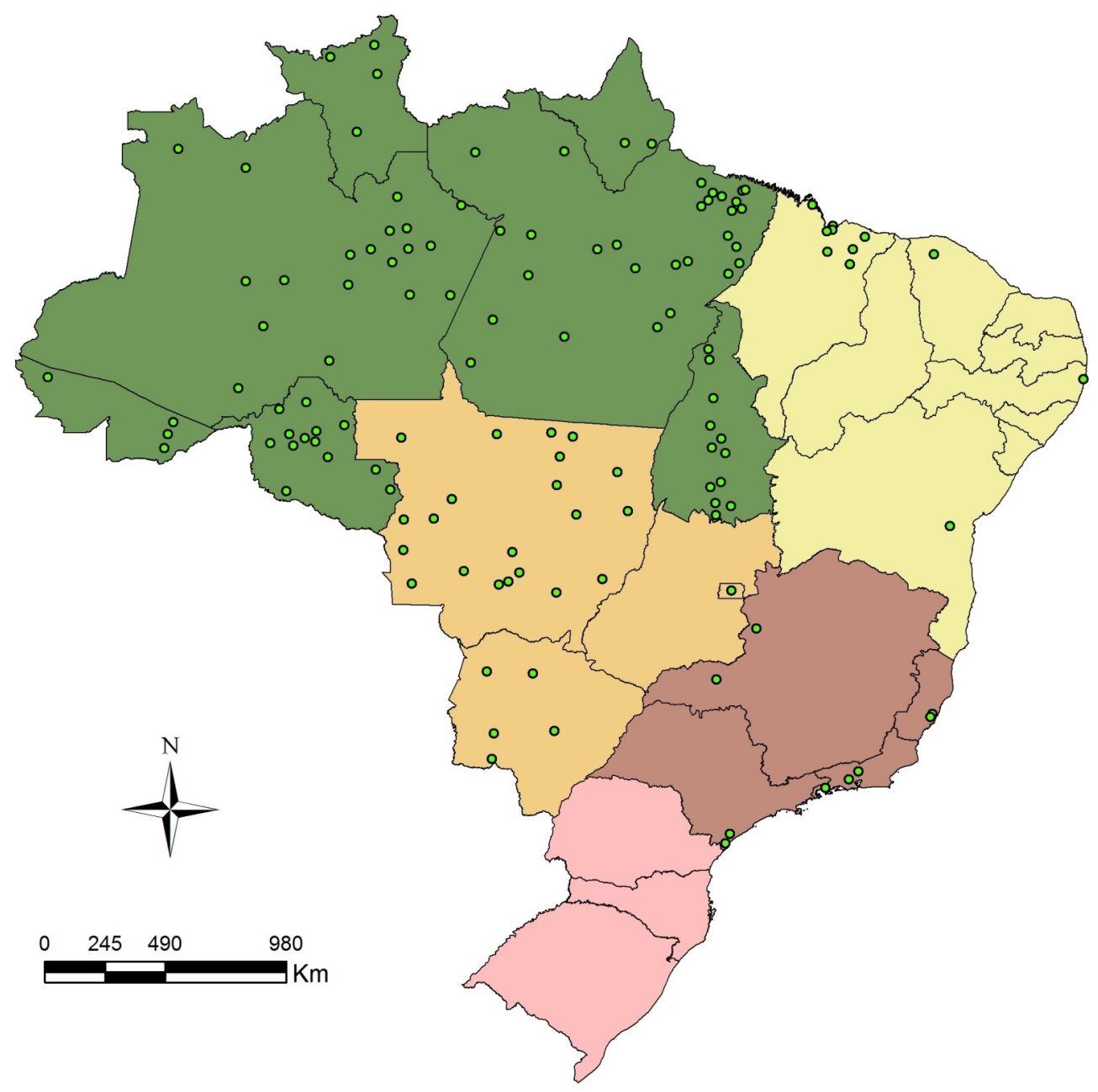

\section{Legend}

\section{Brazilian Regions Municipalities with ACL Vectors}

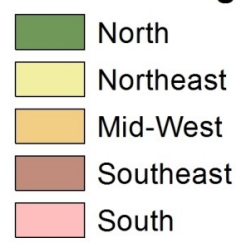

- Lutzomyia (N.) flaviscutellata

Figure 5. Brazilian municipalities with Lutzomyia (Nyssomyia) flaviscutellata occurrence 


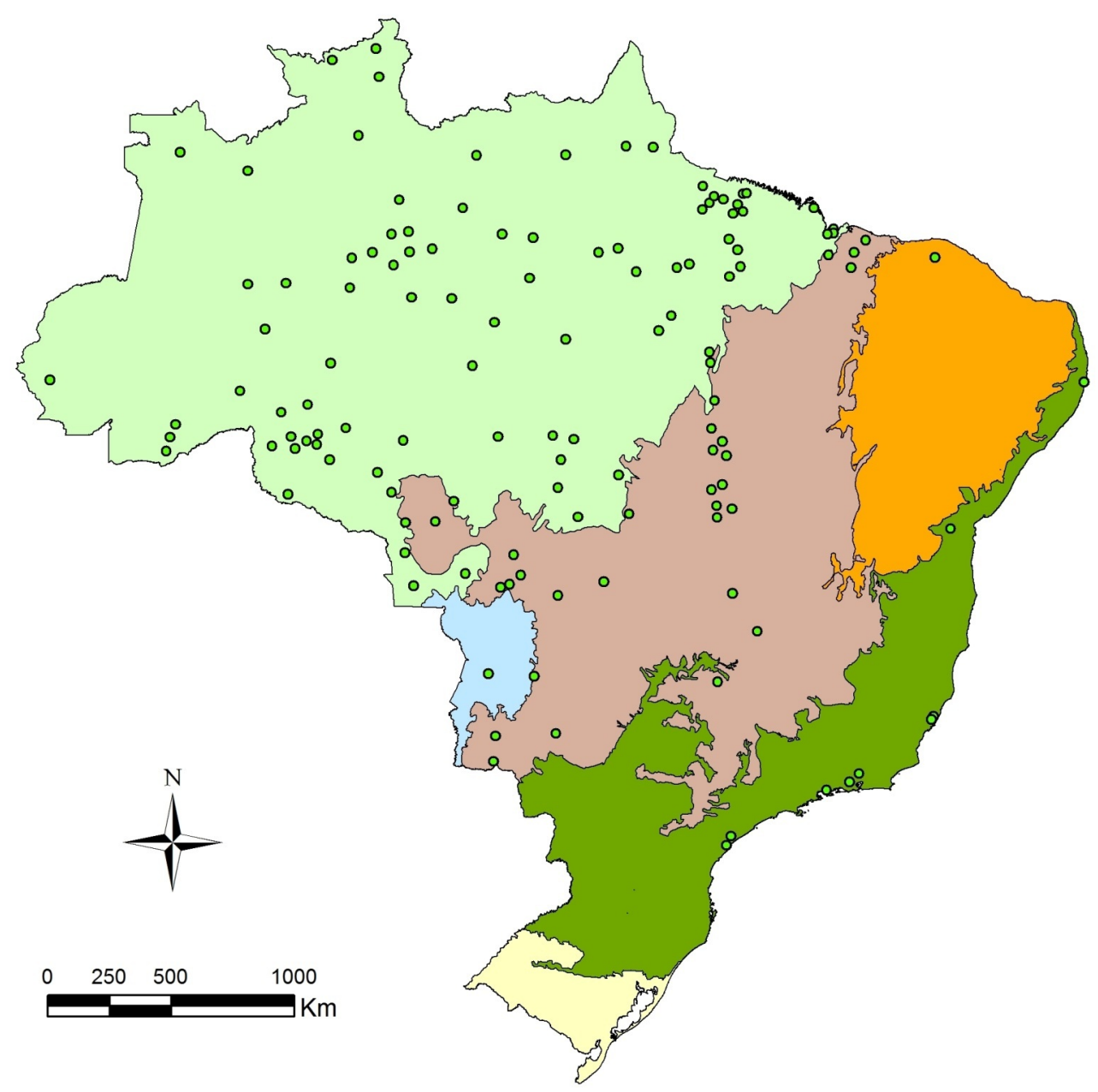

\section{Legend}

\section{Biomes}

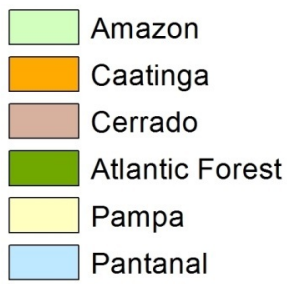

\section{Municipalities with ACL Vectors}

- Lutzomyia (N.) flaviscutellata

Figure 6. Brazilian municipalities with Lutzomyia (Nyssomyia) flaviscutellata occurrence and biomes 
In Southeast region, another ecotourism area was surveyed, in Rio de Janeiro state, Atlantic Forest biome. In Angra dos Reis municipality, the state's biggest continental island - Ilha Grande - has records of sporadic ACL cases since the first outbreak in the decade of 1970. At the time of the ACL outbreak, the sand fly fauna was monitored and L. (N.) flaviscutellata was captured inside the forest with Disney traps, baited with Proechimys rodents [90]. Over three decades later, the same localities were surveyed, and L. (N.) flaviscutellata was captured inside the forest and in peridomestic areas of several fisherman villages in Ilha Grande [65]. Even though there are no recorded human cases of Leishmania (L.) amazonensis infection in Ilha Grande, one DCL case was recorded in 2007 in Paraty, a municipality neighbor to Angra dos Reis [91].

\section{Conclusion: Two American cutaneous leishmaniasis vectors as drivers of its geographical expansion in Brazil}

Both Lutzomyia (N.) whitmani and L. (N.) flaviscutellata are widely spread in Brazilian territory. Each one with its particular epidemiological importance, their geographical distributions overlap areas of ACL occurrence in Brazil (Figure 7).

Since it has a wide geographical distribution and it is associated with two ACL parasites (Leishmania (V.) braziliensis and Leishmania (V.) shawi), currently, Lutzomyia (N.) whitmani is considered the most important ACL vector in Brazil. Its importance is due mainly to its role in transmission cycles related with ACL epidemiological pattern 2 (sylvatic/occupational and impacted areas). This sand fly species was found in several localities associated with areas of environmental changes of different origins, such as deforestation, road constructions, human settements and agricultural activities. This epidemiological pattern is frequently observed in Brazil, and constitutes the main evidence of the disease's geographical spreading.

Lutzomyia (N.) flaviscutellata, with evidences of dispersion to peridomestic areas especially in the Cerrado biome, confirms the ruralization process of the previously considered strictly sylvatic cycle of Leishmania (L.) amazonensis. The possibility of this enzootic cycle to be maintained in secondary forests and even become peridomestic was previously discussed [69]. This could be happening, in part, because of the adaptation process of the vector to man-modified environments. At first, it would be logical to think that a strictly sylvatic cycle would disappear with deforestation of primary forests [92], but the Leishmania (L.) amazonensis cycle shows evidences of occurrence in secondary forests and peridomestic areas, where the vector could be dispersing to domestic animal shelters [22].

Considering the great challenge that is controlling $\mathrm{ACL}$, a disease with complex epidemiology directly associated with environmental changes, studies that aim to characterize and monitor its spatial and temporal trends can support the Epidemiological and Entomological Surveillance actions of Health Departments. These studies can help to identify receptive areas for new ACL outbreaks and population groups at higher risk of infection, so that control actions can be better planned and more effective. 


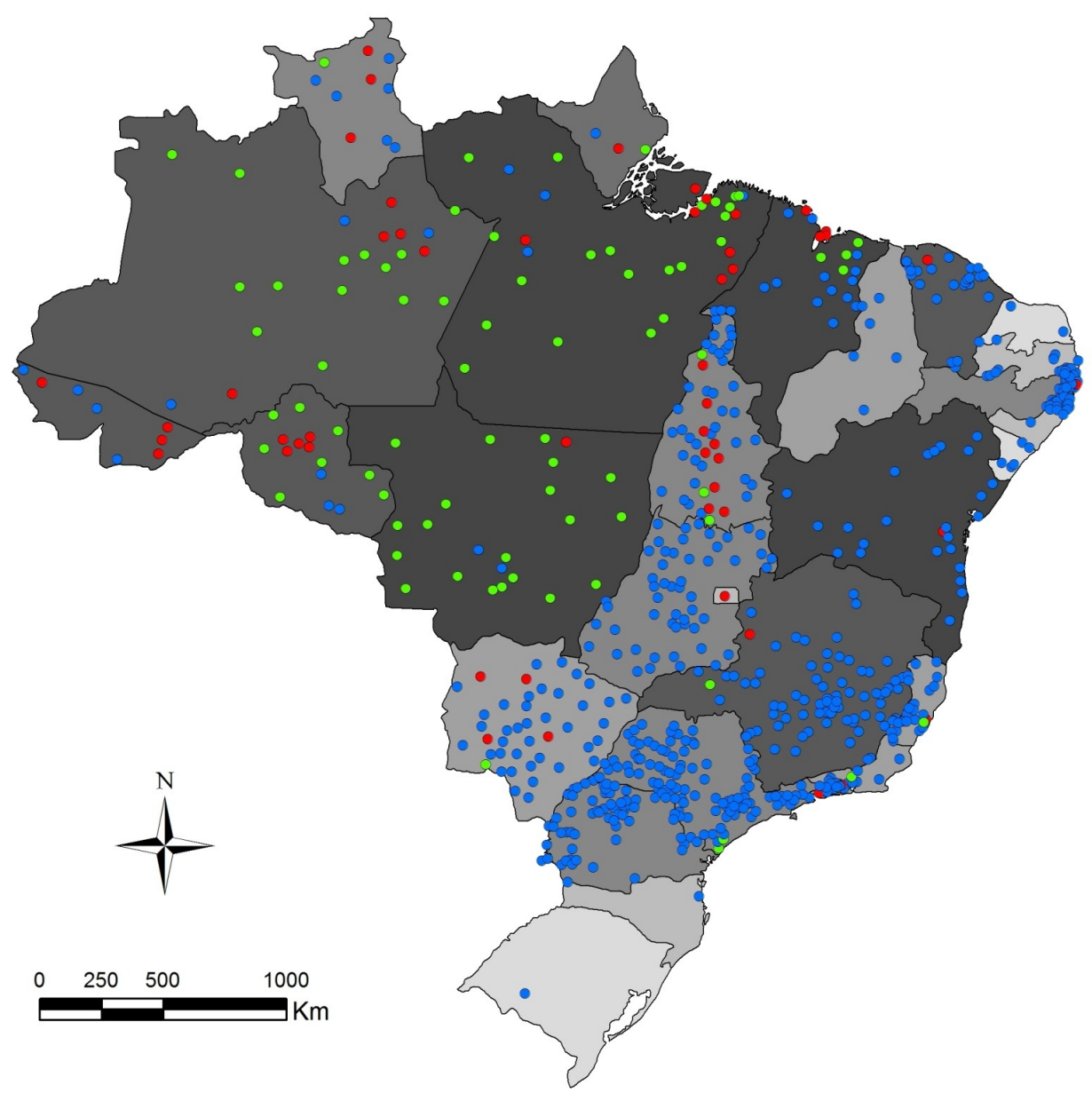

\section{Legend}

\section{ACL Human Cases in 2003-2012}

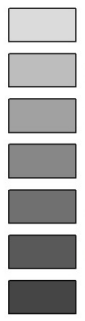

$100-220$

$221-720$

$721-1700$

$1701-5450$

$5451-6770$

$6770-21530$

$21531-41774$

\section{Municipalities with ACL Vectors}

- Lutzomyia (N.) whitmani

- Lutzomyia (N.) flaviscutellata

- L. (N.) whitmani and L. (N.) flaviscutellata

Figure 7. Brazilian municipalities with Lutzomyia (Nyssomyia) whitmani and Lutzomyia (Nyssomyia) flaviscutellata occurrence and American Cutaneous Leishaniasis human cases recorded by state in the past ten years (2003-2012) 


\section{Acknowledgements}

To Mônica Magalhães, from Instituto de Comunicação e Informação Científica e Tecnológica em Saúde (FIOCRUZ) and Thiago Vasconcelos, from Instituto Evandro Chagas. To Fundação Carlos Chagas Filho de Amparo à Pesquisa do Estado do Rio de Janeiro (FAPERJ) and Instituto Oswaldo Cruz (FIOCRUZ) for financial support.

\section{Author details}

Elizabeth F. Rangel, Simone M. da Costa and Bruno M. Carvalho*

*Address all correspondence to: brunomc@ioc.fiocruz.br

Oswaldo Cruz Institute, FIOCRUZ, Rio de Janeiro, Brazil

\section{References}

[1] Walsh JF, Molyneux DH, Birley MH. Deforestation: effects on vector-borne disease. Parasitology 1993;106(Suppl) 55-75.

[2] Patz JA, Thaddeus KG, Geller N, Vittor AY. Effects of environmental change on emerging parasitic diseases. International Journal for Parasitology 2000;30 1395-1405.

[3] McMichael AJ. Environmental and social influences on emerging infectious diseases: past, present and future. Philosophical Transactions of the Royal Society London B 2004;359 1049-1058.

[4] Shaw J. How climatic and environmental variations affect the eco-epidemiology of the leishmaniases and their control. In: III Workshop de Genética e Biologia Molecular de Insetos Vetores de Doenças Tropicais; Recife (PE), Brasil 2008; p13.

[5] Ashford RW. The leishmaniasis as emerging and reemerging zoonoses. International Journal for Parasitol 2000;30 1269-1281.

[6] Dujardin JC. Risk factors in the spread of leishmaniases: towards integrated monitoring? Trends in Parasitology 2006;22(1) 4-6.

[7] WHO - World Health Organization. Control of the leishmaniases: report of a meeting of the WHO Expert Committee on the Control of Leishmaniases, Geneva, 22-26 March 2010 (WHO Technical Report Series, nº 949). Geneva: WHO Press; 2010.

[8] Peters W, Killick-Kendrick R. The Leishmaniasis in Biology and Medicine, London: Academic Press; 1987. 
[9] Alvar J, Vélez ID, Bern C, Herrero M, Desjeux P, Cano J, Jannin J, den Boer M. Leishmaniasis worldwide and global estimates of its incidence. PlosOne 2012;7(5) e35671.

[10] Naucke TJ, Pesson B. Presence of Phlebotomus (Transphlebotomus) mascittii Grassi, 1908 (Diptera : Psychodidae) in Germany. Parasitolgy Research 2000;86(4) 335-336.

[11] Muzón J, Spinelli GR, Salomón OD, Rossi GC. A first record of Phlebotominae from Argentinean Patagonia (Diptera: Psychodidae: Phlebotominae). Memórias do Instituto Oswaldo Cruz 2002;97(6) 797-798.

[12] Ready PD, Lainson R, Shaw JJ. Habitat and seasonality of Psychodopygus wellcomei help incriminate it as a vector of Leishmania braziliensis in Amazonia and northeast Brazil. Transactions of the Royal Society of Tropical Medicine and Hygiene 1984;78 543-544.

[13] Alves VR, Freitas RA, Santos FL, Barrett TV. Diversity of sandflies (Psychodidae: Phlebotominae) captured in sandstone caves from Central Amazonia, Brazil. Memórias do Instituto Oswaldo Cruz 2011;106(3) 353-359.

[14] Campbell-Lendrum DH, Brandão-Filho SP, Pinto MC, Vexenat A, Ready PD, Davies CR. Domesticity of Lutzomyia whitmani (Diptera: Psychodidae) populations: Field experiments indicate behavioural differences. Bulletin of Entomological Research 2000;90 41-48.

[15] Killick-Kendrick R. The Biology and Control of Phlebotomine Sand Flies. Clinics Dermatology 1999;17(3) 279-289.

[16] Afonso MMS, Chaves SAM, Rangel EF. Evaluation of feeding habits of haematophagous insects, with emphasis on Phlebotominae (Diptera: Psychodidae), vectors of Leishmaniasis - Review. Trends in Entomology 2012;8 125-136.

[17] Ready PD. Biology of Sand Flies as Vectors of Disease Agents. Annual Review of Entomology 2013;58 227-250.

[18] Young DG, Duncan MA. Guide to the identification and geographic distribution of Lutzomyia sandflies in Mexico, the West Indies, Central and South America (Diptera:Psychodidae). Memoirs of the American Entomological Institute 1994;54 1-881.

[19] Rangel EF. Tropical Diseases, Society and the Environment. SAREC Documentation/ TDR, 1995; 103-110.

[20] Rangel EF, Lainson R. Ecologia das Leishmanioses: Transmissores de Leishmaniose Tegumentar Americana. In: Rangel EF, Lainson R (eds.) Flebotomíneos do Brasil, Rio de Janeiro: Fiocruz; 2003. p291-310.

[21] Costa, SM, Cechinel M, Bandeira V, Zannuncio JC, Lainson R, Rangel EF. Lutzomyia (Nyssomyia) whitmani s.l. (Antunes \& Coutinho, 1939) (Diptera: Psychodidae: Phlebotominae) and the Epidemiology of American Cutaneous Leishmaniasis in Brazil. Memórias do Instituto Oswaldo Cruz 2007;102(2) 149-153. 
[22] Rangel EF, Lainson R. Proven and putative vectors of American cutaneous leishmaniasis in Brazil: aspects of their biology and vectorial competence. Memórias do Instituto Oswaldo Cruz 2009;104(7) 937-954.

[23] Brasil. Ministério da Saúde. Secretaria de Vigilância em Saúde. Departamento de Vigilância Epidemiológica. Manual de Vigilância da Leishmaniose Tegumentar Americana 2a. ed. Brasília: Editora do Ministério da Saúde; 2007.

[24] Antunes PCA, Coutinho JO. Notas sobre flebótomos sul-americanos. II. Descrição de Flebotomus whitmani n. sp. e da armadura bucal de algumas espécies. Boletim de Biologia de São Paulo 1939;4 448-453.

[25] Pessoa SB, Coutinho JO. Infecção natural e experimental dos flebótomos pela Leishmania braziliensis no Estado de São Paulo. O Hospital 1941;20 25-35.

[26] Barretto MP. Observações sobre a biologia em condições naturais dos flebótomos do estado de São Paulo (Diptera, Psychodidae). PhD thesis. University of Public Health São Paulo; 1943.

[27] Forattini OP. Entomologia Médica, 4⿳⺈ Volume: Psychodidae. Phlebotominae. Leishmanioses. Bartonelose. São Paulo: Edgard Blücher and Universidae de São Paulo; 1973.

[28] Forattini OP. Novas observações sobre a biologia de flebótomos em condições naturais (Diptera, Psychodidae). Arquivos da Faculdade de Higiene e Saúde Pública 1960;25 209-215.

[29] Costa SM, Cechinel M, Magalhães MAFM, Barcellos C, Rangel EF. Use of geoprocessing techniques in the analysis of the distribution of Lutzomyia (Nyssomyia) whitmani (Diptera:Psychodidae:Phlebotominae) in association with vegetation and the epidemiological circuits of American Cutaneous Leishmaniasis (ACL) in Brazil. In: International Symposium on Phlebotomine Sandflies, 25-30 Apr 2011, Kuşadas1, Turkey. 2011.

[30] Costa SM, Cordeiro JP, Rangel EF. Distribuição espacial de Lutzomyia (Nyssomyia) whitmani (Diptera;Phychodidae;Phlebotominae), vetor de Leishmaniose Tegumentar Americana, em associação com os diferentes biomas brasileiros. In: $1^{\text {a }}$ Conferência Brasileira em Saúde Silvestre e Humana, 24-26 Oct 2012, Rio de Janeiro, Brazil. 2012.

[31] Taniguchi HH, Tolezano JE, Corrêa FMA, Morales RAP, Veiga RMO, Marassa AM. Epidemiologia da leishmaniose tegumentar americana no Estado de São Paulo, Brasil. I. Composição da fauna flebotomínica no Município de São Roque, Região de Sorocaba. Revista do Instituto Adolfo Lutz 1991;51 23-30.

[32] Taniguchi HH, Tolezano JE. American cutaneous Leishmaniasis in São Paulo State. II Seasonal fluctuation of Phlebotominae sandflies species in São Roque Country. Memórias do Instituto Oswaldo Cruz 1988;83(Supp.1) 201. 
[33] Souza NA, Vilela ML, Andrade-Coelho CA, Rangel EF. The Phlebotominae sand fly (Diptera: Psychodidae) fauna of two Atlantic Rain Forest Reserves in the State of Rio de Janeiro,Brazil. Memórias do Instituto Oswaldo Cruz 2001;96(3): 319-324.

[34] Souza NA, Andrade-Coelho CA, Vilela ML, Peixoto AA, Rangel EF. Seasonality of Lutzomyia intermedia and Lutzomyia whitmani (Diptera: Psychodidae: Phlebotominae), occurring sympatrically in area of Cutaneous Leishmaniasis in the State of Rio de Janeiro, Brazil. Memórias do Instituto Oswaldo Cruz 2002;97(6) 759-765.

[35] Mayrink W, Willians P, Coelho MV, Dias M, Martins AV, Magalhães PA, Costa CA, Falcão AR, Melo MN, Falcão AL. Epidemiology of dermal leishmaniasis in the Rio Doce Valley, State of Minas Gerais, Brazil. Annals of Tropical Medicine and Parasitology 1979;73 123-137.

[36] Falqueto A. Especificidade alimentar de flebotomíneos em duas áreas endêmicas de leishmaniose tegumentar no Estado do Espírito Santo. PhD thesis. Fundação Oswaldo Cruz. Rio de Janeiro; 1995.

[37] Luz E, Membrive N, Castro EA, Dereure J, Pratlong F, Dedet JA, Pandey A, ThomazSoccol V. Lutzomyia whitmani (Diptera: Psychodidae) as vector of Leishmania (V.) braziliensis in Paraná state, southern Brazil. Annals of Tropical Medicine \& Parasitology 2000;94(6) 623-631.

[38] Barretto AC, Vexenat JA, Cuba-Cuba CA, Marsden PD. Fauna flebotomínica de uma região endêmica de leishmaniose cutâneo-mucosa, no Estado da Bahia. In: IX Reunião Anual sobre Pesquisa Básica em Doenças de Chagas; 1982. p147.

[39] Vexenat JA, Barretto AC, Rosa AC. Infecção experimental de Lutzomyia whitmani em cães infectados com Leishmania braziliensis braziliensis. Memórias do Instituto Oswaldo Cruz 1986;81 125-126.

[40] Azevedo ACR, Rangel EF. Study of sandfly species (Diptera: Psychodidae: Phlebotominae) in focus of cutaneous leishmaniasis in the Municipality of Baturité, Ceará, Brasil. Memórias do Instituto Oswaldo Cruz 1991;86(4) 405-410.

[41] Azevedo ACR, Rangel EF, Costa EM, David J, Vasconcelos AW, Lepes VG. Natural infection of Lutzomyia (Nyssomyia) whitmani (Antunes \& Coutinho, 1939) by Leishmania of the braziliensis complex in Baturite, Ceará State, northeast Brazil. Memórias do Instituto Oswaldo Cruz 1990;85: 251.

[42] Queiroz RG, Vasconcelos IA, Vasconcelos AW, Pessoa FA, Souza RN, David JR. Cutaneous leishmaniasis in Ceará State in northeasten Brazil: incrimination of Lutzomyia whitmani (Diptera: Psychodidae) as a vector of Leishmania braziliensis in Baturité municipality. The American Journal of Tropical Medicine and Hygiene 1994;50 693-698.

[43] Hoch A, Ryan L, Vexenet JA, Rosa AC, Barretto AC. Isolation of Leishmania braziliensis braziliensis and other trypanosomatids from Phlebotomines in mucocutaneous 
leishmaniases endemic area Bahia, Brazil. Memórias do Instituto Oswaldo Cruz 1986;81(Suppl) BI 44.

[44] Ryan L, Vexenet A, Marsdem PD, Lainson R. The importance of rapid diagnoses of new cases of cutaneous leishmaniasis in pinpointing the sand fly vector. Transactions of the Royal Society of Tropical Medicine and Hygiene 1990;84: 786.

[45] Nunes VLB, Dorval MEC, RC, Oshiro ET, Noguchi Arão LB, Filho GH, Espínola MA, Cristaldo G, Rocha HC, Serafini LN, Santos D. Estudo epidemiológico sobre Leishmaniose Tegumentar (LT) no Município de Corguinho, Mato Grosso do Sul - estudos na população humana. Revista da Sociedade Brasileira de Medicina Tropical1995;28(3) 185-193.

[46] Galati EAB, Nunes VLB, Dorval MEC, Oshiro ET, Cristaldo G, Espínola MA, Rocha HCR, Garcia WB. Estudo dos flebotomíneos (Diptera, Psychodidae), em área de leishmaniose tegumentar, no Estado de Mato Grosso do Sul, Brasil. Revista de Saúde Pública 1996;30 115-128.

[47] Lainson R, Shaw JJ, Ward RD, Ready PD, Naiff RD. Lesmmaniases in Brazil: XIII. Isolation of Leishmania from armadillos (Dasypus novemcinctus), and observation on the epidemiology of cutaneous leismaniasis in north Pará State. Transactions of the Royal Society of Tropical Medicine and Hygiene 1979;73 239-242.

[48] Ready PD, Lainson R, Shaw JJ, Ward D. The ecology of Lutzomyia umbratilis (Ward \& Fraiha, 1977) (Diptera: Psychodiade), the major vector to man Leishmania braziliensis guyanensis in north-eastern Amazonian Brazil. Bulletin of Entomological Research $1986 ; 7621-40$

[49] Shaw JJ, Ishikawa EAY, Lainson R, Braga RR, Silveira FT. Cutaneous leishmaniasis of man due to Leishmania (Viannia) shawi Lainson, De Souza, Póvoa, Ishikawa \& Silveira in Pará State, Brazil. Annales de Parasitologie Humaine et Comparée 1991;66 243-246.

[50] Lainson R, Braga RR, De Souza AA, Pôvoa MM, Ishikawa EA, Silveira FT. Leishmania (Viannia) shawi sp. n., a parasite of monkeys, sloths and procyonids in Amazonian Brazil. Annales de Parasitologie Humaine et Comparée 1989;64(3) 200-207.

[51] Mangabeira O. 7a. Contribuição ao estudo dos Flebotomus (Diptera: Psychodidae). Descrição dos machos de 24 novas espécies. Memórias do Instituto Oswaldo Cruz 1942;37(2) 111-218.

[52] Sherlock IA, Carneiro M. Algumas fêmeas de Phlebotomus do Brasil (Diptera, Psychodidae). Memórias do Instituto Oswaldo Cruz 1962;60(3) 421-435.

[53] Fairchild GB, Theodor O. On Lutzomyia flaviscutellata (Mangabeira) and L. olmeca (Vargas and Diaz-Najera) (Diptera: Psychodidae). Journal of Medical Entomology 1971;8(2) 153-159.

[54] Floch H, Abonnenc E. Phlébotomes de Guyane Française. V. Institute Pasteur de la Guyane, Publ. No. 61. Cayenne: Institute Pasteur; 1943. 
[55] Barreto MP. Sôbre a sinonímia de flebótomos americanos (Diptera, Psychodidae). Primeira nota. Revista Brasileira de Biologia 1946;6: 527-536.

[56] Vargas L, Días-Nájera A. Phlebotomus farilli n. sp., Ph. humboldi n. sp. y Ph. olmecus n. sp. de Mexico (Diptera: Psychodidae). Revista del Instituto de Salubridad y Enfermedades Tropicales1959;19 141-149.

[57] Young DG, Arias JR. A new phlebotomine sand fly in the Lutzomyia flaviscutellata complex (Diptera: Psychodidae) from northern Brazil. Journal of Medical Entomology 1982;19(2) 134-138.

[58] Lewis DJ. The Lutzomyia flaviscutellata complex (Diptera: Psychodidae). Journal of Medical Entomology 1975;12(3) 363-368.

[59] Galati EAB. Classificação de Phlebotominae. In: Rangel EF, Lainson R (eds.) Flebotomíneos do Brasil. Rio de Janeiro: Editora Fiocruz; 2003. p23-52.

[60] Costa JML, Cunha AK, Gama MEA, Saldanha ACR. Leishmaniose cutânea difusa (LCD) no Brasil: revisão. Anais Brasileiros de Dermatologia 1998;73(6) 565-576.

[61] Lainson R, Shaw JJ. Leishmaniasis in Brazil I. Observations on enzootic rodent leishmaniasis - Incrimination of Lutzomyia flaviscutellata (Mangabeira) as the vector in the lower Amazonian Basin. Transactions of the Royal Society of Tropical Medicine and Hygiene 1968;62 385-395.

[62] Shaw JJ, Lainson R. Leishmaniasis in Brazil: II. Observations on enzootic rodent leishmaniasis in the lower Amazon region - the feeding habits of the vector, Lutzomyia flaviscutellata, in reference to man, rodents and other animals. Transactions of the Royal Society of Tropical Medicine and Hygiene 1968;62(3) 396-405.

[63] Disney RHL. A trap for phlebotomine sandflies attracted to rats. Bulletin of Entomological Research 1966;56 445-451.

[64] Andrade ARO, Nunes VLB, Galati EAB, Arruda CCP, Santos MFC, Rocca MEG, Aquino RB. Epidemiological study on leishmaniasis in an area of environmental tourism and ecotourism, State of Mato Grosso do Sul, 2006-2007. Revista da Sociedade Brasileira de Medicina Tropical 2009;42(5) 488-493.

[65] Carvalho BM. Aspectos da ecologia de potenciais vetores de leishmanioses (Diptera: Psychodidae: Phlebotominae) na Ilha Grande, Angra dos Reis, Rio de Janeiro. MS dissertation. Instituto Oswaldo Cruz. Rio de Janeiro; 2011.

[66] Vilela ML, Azevedo CG, Carvalho BM, Rangel EF. Phlebotomine fauna (Diptera: Psychodidae) and putative vectors of leishmaniases in impacted area by hydroelectric plant, state of Tocantins, Brazil. PLoS One 2011;6(12) e27721.

[67] Vilela ML, Pita-Pereira D, Azevedo CG, Godoy RE, Britto C, Rangel EF. The phlebotomine fauna (Diptera: Psychodidae) of Guaraí, state of Tocantins, with an emphasis 
on the putative vectors of American cutaneous leishmaniasis in rural settlement and periurban areas. Memórias do Instituto Oswaldo Cruz 2013;108(5) 578-585.

[68] Ready PD, Lainson R, Shaw JJ. Leishmaniasis in Brazil. XX: Prevalence of "enzootic rodent leishmaniasis" (Leishmania mexicana amazonensis) and apparent absence of pian-bois (Le. braziliensis guyanensis), in plantations of introduced tree species and in other non-climax forests in eastern Amazonia. Transactions of the Royal Society of Tropical Medicine and Hygiene 1983;77 775-785.

[69] Lainson R, Shaw JJ, Silveira FT, de Souza AA, Braga RR, Ishikawa EA. The dermal leishmaniases of Brazil, with special reference to the eco-epidemiology of the disease in Amazonia. Memórias do Instituto Oswaldo Cruz 1994;89(3) 435-443.

[70] Shaw JJ, Lainson R. Leishmaniasis in Brazil: VI. Observations on the seasonal variations of Lutzomyia flaviscutellata in different types of forest and its relationship to enzootic rodent leishmaniasis (Leishmania mexicana amazonensis). Transactions of the Royal Society of Tropical Medicine and Hygiene 1972;66(5) 709-717.

[71] Shaw JJ, Lainson R, Ward RD. Leishmaniasis in Brazil. VII. Further observations on the feeding habitats of Lutzomyia flaviscutellata (Mangabeira) with particular reference to its biting habits at different heights. Transactions of the Royal Society of Tropical Medicine and Hygiene 1972;66(5) 718-723.

[72] Feitosa MAC, Castellon EG. Fauna de flebotomíneos (Diptera: Psychodidae) em fragmentos florestais ao redor de conjuntos habitacionais na cidade de Manaus, Amazonas, Brasil. II. Estratificação horizontal. Acta Amazônica 2004;34(1) 121-127.

[73] Lainson R, Shaw JJ, Silveira FT, Fraiha H. Leishmaniasis in Brazil. XIX. Visceral leishmaniasis in the Amazon region, and the presence of Lutzomyia longipalpis on the Island of Marajó, Pará State. Transactions of the Royal Society of Tropical Medicine and Hygiene 1983;77(3) 323-330.

[74] Arias JR, Freitas RA. The known geographical distribution of sand flies in the State of Acre, Brasil (Diptera: Psychodidae). Acta Amazonica 1982;12 401-408.

[75] Azevedo ACR, Costa SM, Pinto MCG, Souza JL, Cruz HC, Vidal J, Rangel EF. Studies on the sandfly fauna (Diptera: Psychodidae: Phlebotominae) from transmission areas of American Cutaneous Leishmaniasis in state of Acre, Brazil. Memórias do Instituto Oswaldo Cruz 2008;103(8) 760-767.

[76] Castellón EG, Arias JR, Freitas RA, Naiff RD. Os flebotomíneos da região amazonica, estrada Manaus-Humaitá, Estado do Amazonas, Brasil (Diptera: Psychodidae; Phlebotominae). Acta Amazônica 1994;24(1-2) 91-102.

[77] Castellón EG, Fé NF, Buhrnheim PF, Fé FA. Flebotomíneos (Diptera, Psychodidae) na Amazônia. II. Listagem das espécies coletadas na bacia petrolífera no Rio Urucu, Amazonas, Brasil, utilizando diferentes armadilhas e iscas. Revista Brasileira de Zoologia 2000;17(2) 455-462. 
[78] Silva DF, Freitas RA, Franco AMR. Diversidade e abundância de flebotomíneos do gênero Lutzomyia (Diptera: Psychodidae) em áreas de mata do nordeste de Manacapuru, AM. Neotropical Entomology 2007;36(1) 138-144.

[79] Alves VR, Freitas RA, Santos FL, Oliveira AFJ, Barrett TV, Shimabukuro PHF. Sand Flies (Diptera, Psychodidae, Phlebotominae) from Central Amazonia and four new records for the Amazonas state, Brazil. Revista Brasileira de Entomologia 2012;56(2) 220-227.

[80] Freitas RA, Naiff RD, Barrett TV. Species diversity and flegellate infections in the sand fly fauna near Porto Grande, state of Amapá, Brazil (Diptera: Psychodidae. Kinetoplastida: Trypanosomatidae). Memórias do Instituto Oswaldo Cruz 2002;97(1) 53-59.

[81] Ryan L. Flebótomos do Estado do Pará, Brasil (Diptera: Psychodidae: Phlebotominae). Tech Doc No. 1, Instituto Evandro Chagas, Belém, Pará, Brazil; 1986.

[82] Gil LHS, Basano AS, Souza AA, Silva MGS, Barata I, Ishikawa EA, Camargo LMA, Shaw JJ. Recent observations on the sand fly (Diptera: Psychodidae) fauna of the state of Rondônia, Western Amazonia, Brazil: the importance of Psychodopygus davisi as a vector of zoonotic cutaneous leishmaniasis. Memórias do Instituto Oswaldo Cruz 2003;98(6) 751-755.

[83] Gil LHS, Araújo MS, Villalobos JM, Camargo LMA, Ozaki LS, Fontes CJF, Ribolla PEM, Katsuragawa TH, Cruz RM, Silva AA, Silva LHP. Species structure of sand fly (Diptera: Psychodidae) fauna in the brazilian western Amazon. Memórias do Instituto Oswaldo Cruz 2009;104(7) 955-959.

[84] Castellón EG, Araújo Filho NA, Fé NF, Alves JMC. Flebotomíneos (Diptera: Psychodidae) no Estado de Roraima, Brazil. II. Espécies coletadas na região Norte. Acta Amazônica 1991;21 45-50.

[85] Castellón EG, Araújo Filho NA, Fé NF, Alves JMC. Flebotomíneos (Diptera: Psychodidae) no Estado de Roraima. III. Listagem das espécies no Estado. Acta Amazônica 1991;21 51-54.

[86] Vilela ML, Azevedo ACR, Costa SM, Costa WA, Motta-Silva D, Grajauskas AM, Carvalho BM, Brahim LRN, Kozlowsky D, Rangel EF. Sand fly survey in the influence area of Peixe Angical hydroeletric plant, state of Tocantins, Brazil. In: 6th International Symposium on Phlebotomine Sandflies, 27-31 Oct 2008, Lima, Peru; 2008.

[87] Dorval MEC, Cristaldo G, Rocha HC, Alves TP, Alves MA, Oshiro ET, Oliveira AG, Brazil RP, Galati EAB, Cunha RV. Phlebotomine fauna (Diptera: Psychodidae) of an American cutaneous leishmaniasis endemic area in the state of Mato Grosso do Sul, Brazil. Memórias do Instituto Oswaldo Cruz 2009;104 695-702.

[88] Dorval MEC, Alves TP, Cristaldo G, Rocha HC, Alves MA, Oshiro ET, Oliveira AG, Brazil RP, Galati EAB, Cunha RV. Sand Fly Captures with Disney traps in area of occurrence of Leishmania (Leishmania) amazonensis in the State of Mato Grosso do Sul, 
mid-western Brazil. Revista da Sociedade Brasileira de Medicina Tropical 2010;43(5) 491-495.

[89] Galati EAB, Nunes VLB, Dorval MEC, Cristaldo G, Rocha HC, Gonçalves-Andrade RM, Naufel G. Attraction of black Shannon trap for phlebotomines. Memórias do Instituto Oswaldo Cruz 2001;96 641-647.

[90] Araújo Filho NA, Sherlock IA, Coura JR: Leishmaniose Tegumentar Americana na Ilha Grande, Rio de Janeiro. V. Observações sobre a biologia dos transmissores em condições naturais. Revista da Sociedade Brasileira de Medicina Tropical 1981;14(4-6) 171-183.

[91] Azeredo-Coutinho RB, Conceição-Silva F, Schubach A, Cupolillo E, Quintela LP, Madeira MF, Pacheco RS, Valete-Rosalino CM, Mendonça SC. First report of diffuse cutaneous leishmaniasis and Leishmania amazonensis infection in Rio de Janeiro State, Brazil. Transactions of the Royal Society Tropical Medicine and Hygiene 2007;101 735-737.

[92] Campbell-Lendrum D, Dujardin JP, Martinez E, Feliciangeli MD, Perez JE, Silans LNMP, Desjeux P. Domestic and peridomestic transmission of American cutaneous leishmaniasis: Changing epidemiological patterns present new control opportunities. Memórias do Instituto Oswaldo Cruz 2001;96(2) 159-162. 
